\title{
Land use Land Cover Change Detection using K-means Clustering and Maximum Likelihood Classification Method in the Javadi Hills, Tamil Nadu, India
}

\author{
M. Sam Navin, L. Agilandeeswari
}

\begin{abstract}
Land use/Land cover (LU/LC) change analysis is the present-day challenging task for the researchers in defining the environmental change across the world in the field of remote sensing and GIS (Geographic Information System). This paper analyzes the LU/LC changes between the years 2009 and 2019 in the region of Javadi Hills located in Tamil Nadu, India. Images from the Indian remote sensing satellite Resourcesat-1 LISS III and American earth observation satellite Landsat-8 were used for analyzing the LU/LC change for the study area. In this work, the classification was performed by using the hybrid approach of unsupervised and supervised classifiers. The classified LU/LC map for the study area defines forest and non-forest covered region. The key objective of this work was to identify the percentage of LU/LC change occurred in our study area for the years 2009 to 2014 and 2014 to 2019. Observing and examining the changes occurred in the study area provides a clear view to the land resources management to take effective measures in protecting the environment.
\end{abstract}

Keywords: Land Use/ Land Cover, Remote Sensing, GIS (Geographic Information System), Supervised and Unsupervised Classifiers, Accuracy Assessment, Change Analysis and Land Resource Management

\section{INTRODUCTION}

Land Use/Land Cover (LU/LC) change plays a crucial role in understanding the impact on the global environment. The LU/LC change detection problem has been sorted out and performed all over the world. LU/LC change analysis is active research in remote sensing environments due to several problems happening in the land surface throughout the world. Few of the problems are deforestation, increase in population growth, and industrialization. The geological structure, slope, altitudes, socio-economic factors, and other ecological conditions determine the LU/LC pattern. The forest survey report states that India had ranked the eighth position across the globe in the year 2017 for achieving the maximum increase of the annual forest area [1]. LU/LC change analysis

Revised Manuscript Received on December 04, 2019

* Correspondence Author

M. Sam Navin, Research Scholar, School of Information Technology and Engineering, Vellore Institute of Technology, Vellore, India. Email: samnavin.m2018@vitstudent.ac.in

L. Agilandeeswari*, Associate Professor, School of Information Technology and Engineering, Vellore Institute of Technology, Vellore, India. Email: agila.1@vit.ac.in was said as a significant key for measuring the changes across the globe for different spatiotemporal scales. Remote Sensing and GIS (Geographic Information System) helps in categorizing and mapping the LU/LC change for different regions with various technolo gies. The LU/LC change pattern should be recognized clearly for better development and management for natural resources. Various methods and procedures have been familiarized with analyzing the LU/LC changes. With the support of different remote sensing and the GIS software, the supervised, unsupervised and fuzzy classification was considered as an extensively applied image classification method for real-time data [2]. Defining and analyzing the LU/LC change over the different periods and generating the better classification accuracy had become the trending part of research in the field of remote sensing. The LU/LC change analysis has been attaining more recognition for worldwide researchers [3]. The image processing methods applied for the satellite data provides dynamic information about the LU/LC change information. For monitoring the variations that occur on the earth's surface, the remote sensing is considered as an efficient and the most reliable environment for the researchers. The analysis of the LU/LC change information provides the advantage for the urban planners to make the appropriate decision in protecting the land resource management [4]. For classifying the satellite images, the different classification techniques were used by the remote sensing researchers. Among those classification methods, the supervised model helps in classifying the satellite image through different pixels by training the image with the reference data for the specified region. Most of the researchers state that the supervised classification technique generally simplifies the precise class descriptions and determines better classification accuracy. The accuracy report of the given study area was generated by comparing the classified data with the reference data. The contingency matrix was evaluated along with kappa statistics, producer, user and the overall accuracy for each classified class [5]. The meticulous process of LU/LC change detection helps in gathering the detailed information about the change of land cover area for different time periods. Image differencing, PCA (Principal Component Analysis) and the post-classification map comparison are said to be the commonly used techniques for analyzing the satellite image [6]. 
In the field of remote sensing, the LU/LC classes are classified and the LU/LC change was analyzed by using the classified map of different time periods. The investigation of both spatial and temporal LU/LC changes helps in processing and managing the natural resources [7]. For monitoring the natural resources and for mapping the forest cover area the satellite data were used across the world. For observing the large areas, the satellite data were acquired, and it helps in identifying the LU/LC change for the specific region for different periods [8].

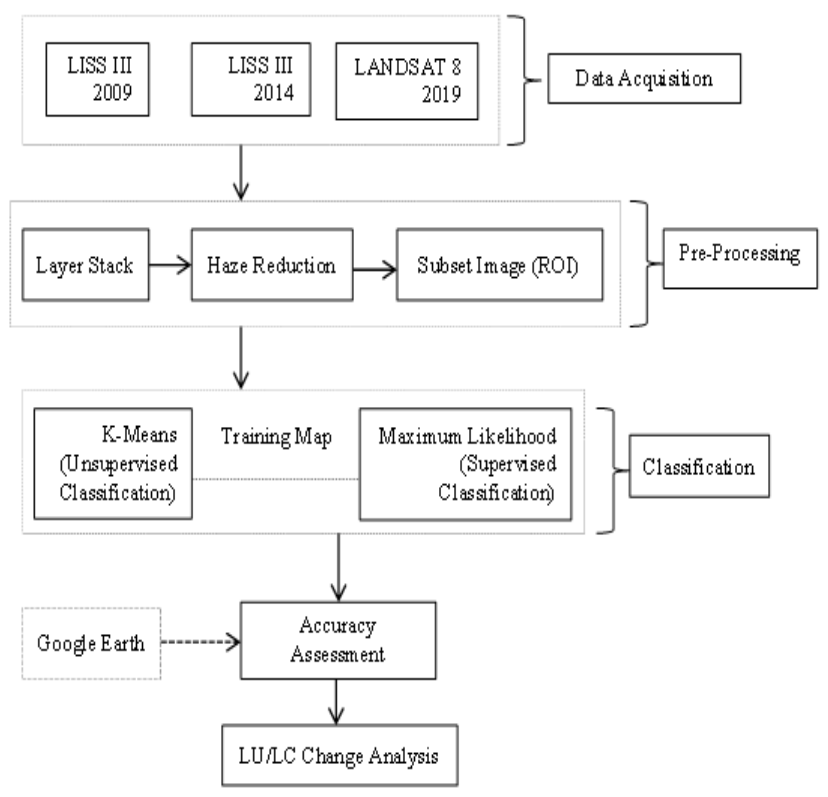

\section{Fig. 1.LU/LC Change Detection Analysis Workflow for} the Javadi Hills

The main objective of this paper was to analyze LU/LC changes between the years 2009 and 2019 in the region of Javadi Hills. Fig. 1 describes the flow of LU/LC change detection analysis for our study area. However, the LU/LC change detection analysis in the Javadi hills located in the Tiruvannamalai district has not been clearly studied and demonstrated over many years. Tiruvannamalai district has earned major importance over the forest cover areas. The main focus of this paper was to assist the land resource management to take the essential steps over the forest growth and to resist external source from the deforestation.

\section{MATERIALS AND METHODS}

\section{A. Study Area}

The present study area was focused in the region of Javadi Hills, Bheemakulam, located in the area of the Eastern Ghats which falls across the region of Tiruvannamalai district, Tamil Nadu, India. The determined portion of the entire district is sheltered with the forest cover where the study area is located near to the Alangayam reserved forest. The Javadi hills lie between the coordinates of between $78^{\circ} 48^{\prime} 22.63^{\prime \prime} \mathrm{E}$ to $78^{\circ} 51^{\prime} 05.51^{\prime \prime} \mathrm{E}$ longitude and $12^{\circ} 33^{\prime} 48.70^{\prime \prime} \mathrm{N}$ to $12^{\circ} 36^{\prime} 12.90^{\prime \prime} \mathrm{N}$ latitude. The thematic representation of our study area is shown in Fig. 2. A Javadi hill is positioned at an altitude averaging among $3,600-3,800$ feet (1100 to $1500 \mathrm{~m}$ ).

The tress in this hilly region produces a variety of forest products and has many homeopathic and fruit-bearing trees. Some of them are castor oil plant, millettia pinnata, smilax regelii etc.

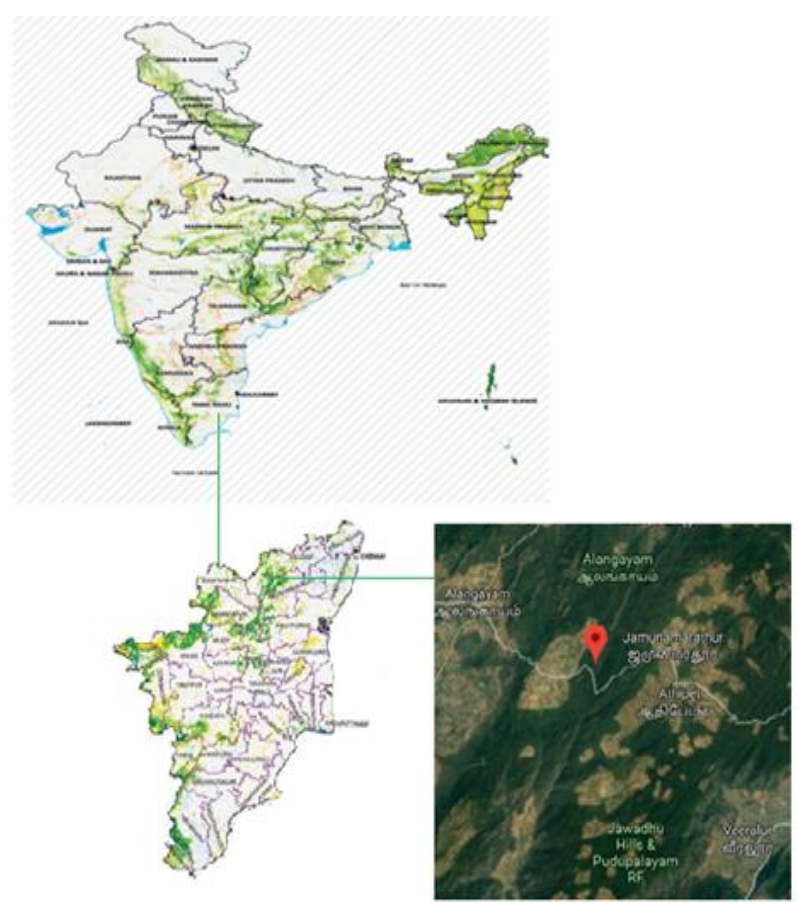

Fig. 2.Location of the Study Area - Javadi Hills

\section{B. Data Acquisition}

The data for this study area covers the LISS-III multispectral images, captured on 19th October 2009, 07th April 2019 and the Landsat 8 OLI- TIRS image captured on 23rd April 2019. Table I displays the characteristics and source of the satellite images. The national and state-level statistics of the forest cover maps are collected from the forest survey of India. Google earth images are used as the reference for the satellite images.

Table- I: Characteristics and Source of the Satellite Images

\begin{tabular}{|c|c|c|c|c|}
\hline $\begin{array}{c}\text { Geospatia } \\
\text { I Input } \\
\text { Data }\end{array}$ & $\begin{array}{l}\text { Path/ } \\
\text { row }\end{array}$ & $\begin{array}{c}\text { Resolutio } \\
\text { n (m) }\end{array}$ & Date & Source \\
\hline $\begin{array}{l}\text { Indian } \\
\text { remote } \\
\text { sensing } \\
\text { satellite } \\
\text { Resources } \\
\text { at-1 LISS } \\
\text { III }\end{array}$ & $\begin{array}{l}101 / \\
064\end{array}$ & 23.5 & $\begin{array}{l}19 \\
\text { October } \\
2009, \\
20 \text { April } \\
2014\end{array}$ & $\begin{array}{l}\text { Bhuvan Indian } \\
\text { Geo-Platform of } \\
\text { ISRO } \\
\text { www.bhuvan.co } \\
\underline{\text { m }}\end{array}$ \\
\hline $\begin{array}{l}\text { American } \\
\text { earth } \\
\text { observatio } \\
\text { n satellite } \\
\text { Landsat-8 }\end{array}$ & $\begin{array}{l}143 / \\
51\end{array}$ & 30 & $\begin{array}{l}23 \text { April } \\
2019\end{array}$ & $\begin{array}{l}\text { U.S. Geological } \\
\text { Survey } \\
\text { https://earthexplo } \\
\text { rer.usgs.gov/ }\end{array}$ \\
\hline
\end{tabular}




\section{Satellite Image Pre-processing and Classification}

Pre-processing of the acquired satellite images is considered as an essential procedure before classification. Layer stacking is used for combining all the required bands of the satellite image into multispectral image. The haze reduction method is used for removing the atmospheric effects on the satellite images. The pre-processing of satellite images helps in removing the noise and other cloud effects. The region of interest (ROI) is acquired from the pre-processed images and then processed for further analysis [4]. In this paper we used layer stacking, atmospheric and radiometric correction for improving the quality and visibility of the satellite images. LU/LC classification was performed for the given study area after pre-processing. The ROI image was selected from the satellite data and processed for classification. For extracting the thematic information from the satellite image, the image classification was performed. The supervised and unsupervised classification technique was performed for classifying the pre-processed satellite images. The hybrid approach helps in attaining better accuracy. We used $\mathrm{K}$-means unsupervised classification method along with supervised maximum likelihood classification to classify the pre-processed satellite images for our study area.

\section{Table- II: LU/LC Classes and their Descriptions for Javadi Hills}

\begin{tabular}{|l|l|}
\hline \multicolumn{1}{|c|}{ LU/LC Class } & \multicolumn{1}{|c|}{ Description } \\
\hline Forest & $\begin{array}{l}\text { Area covered with tress, bushes and other } \\
\text { variety of shrubs. }\end{array}$ \\
\hline Non-Forest & $\begin{array}{l}\text { It contains agricultural fields, vegetation and } \\
\text { other barren lands. }\end{array}$ \\
\hline
\end{tabular}

Among different supervised classifiers, the maximum likelihood classification was considered as the well-known technique which had been used extensively for classifying the pre-processed satellite image. The maximum likelihood classifier determines each pixel of the satellite image should belong to the specific class for conquering the thematic information. The maximum likelihood classifier or Bayesian decision rule assumes the statistics for each LU/LC class in the acquired satellite images are normally distributed, and it helps in calculating the probability that the each pixel belongs to some specific LU/LC class. [9] - [12]. K-Means was the well-known unsupervised classification method that helps in minimizing the squared error function and solves the cluster problems. K- Means was the fast and robust method that gives the finest result when the data gets separated or distributed from each other [13] [14].

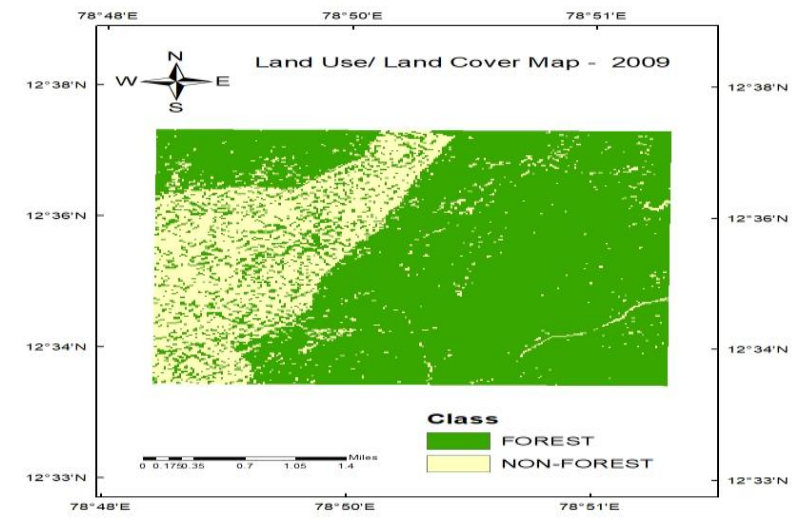

Fig. 3.Land Use/ Land Cover Map - 2009

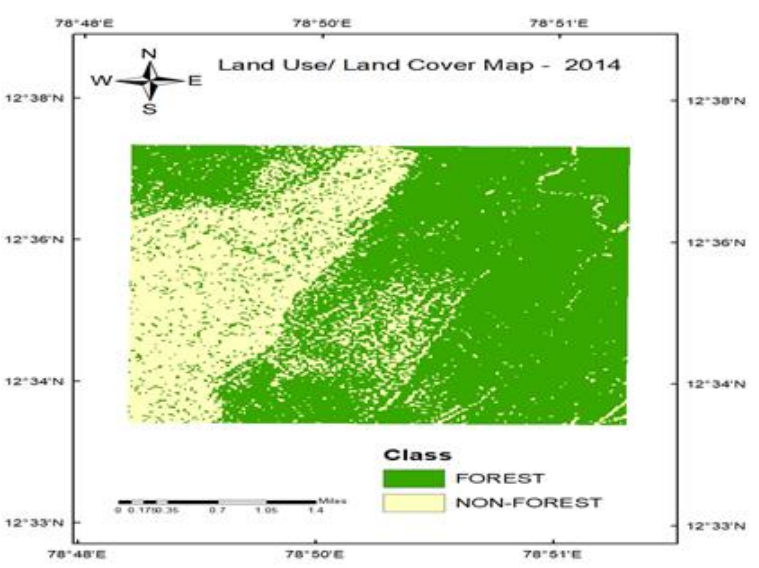

Fig. 4.Land Use/ Land Cover Map - 2014

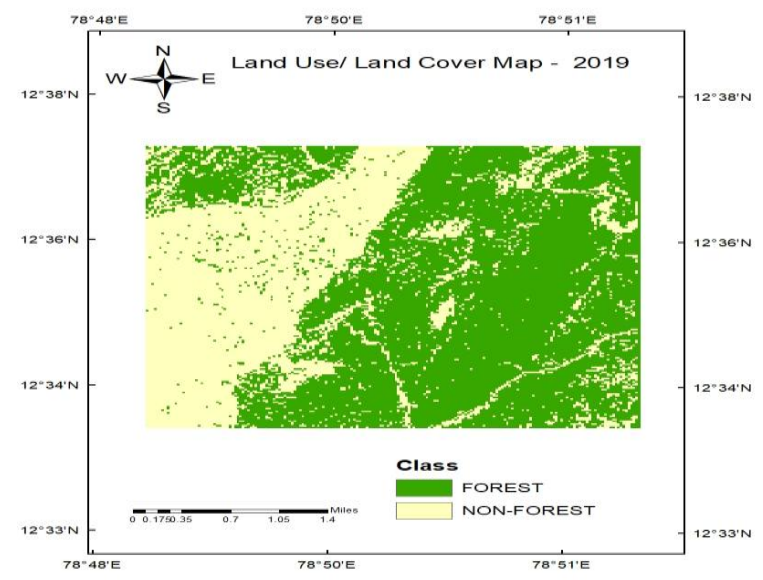

Fig. 5.Land Use/ Land Cover Map - 2019

The multispectral image for the given study area was classified as forest and non-forest cover region and it was shown in Table II. By using the result of the unsupervised K-means method, the supervised maximum likelihood classification was trained and processed. The classification results were shown in Fig. 3, 4 and 5. The result produces better classification accuracy by using this hybrid approach. The key idea of this paper was to identify the forest and non-forest cover region of our study area. 
Land use Land Cover Change Detection using K-means Clustering and Maximum Likelihood Classification Method in the Javadi Hills, Tamil Nadu, India

\section{RESULT AND DISCUSSION}

This work involved the analysis of LU/LC changes that occurred in the Javadi Hills during 2009, 2014 and 2019. Experimentation was conducted on satellite images for 2009 , 2014 and 2019 for analyzing the LU/LC changes in the forest and non-forest covered regions of Javadi Hills. All experiments were conducted using RStudio and geospatial processing software like ArcGIS and Google Earth Engine on Intel Xeon processor $2.90 \mathrm{GHz} \mathrm{CPU}$ along with $128 \mathrm{~GB}$ RAM in Windows 10 (64 bit) environment.

\section{A. Accuracy Assessment}

An accuracy assessment should be done for the better recognition of the classified images. The accuracy was calculated by comparing the classification results with the reference data [15] - [18]. The hybrid approach of K- Means and Maximum Likelihood Classification method was performed in this work and the 256 random sampling points were collected for each identified LU/LC class to assess the accuracy. The reference points obtained were observed with the Google earth images which were acquired for the consistent periods of 19th October 2009, 20th April 2014 and 23rd April 2019. The confidence of the result was determined by the accuracy assessment. The user, producer and overall accuracy report are generated along with the result of kappa statistics. The accuracy assessment of the classified satellite images for the year 2009, 2014 and 2019 are presented in Table III. For each class, the overall accuracy was attained and they were as follows: $95.70 \%$ for the year $2009,91.02 \%$ for the year 2014 and $96.48 \%$ for the year 2019. The kappa statics was obtained and the values are as follows: 0.8982 for the year 2009, 0.8014 for the year 2014 and 0.9196 for the year 2019. The accuracy results demonstrate the good sign-in of the classified image concerning the Google earth image.

Table- III: Accuracy Assessment of the classified images for the year 2009, 2014 and 2019

\begin{tabular}{|c|c|c|c|c|c|c|}
\hline \multirow{2}{*}{ LU/ } & \multicolumn{2}{|c|}{2009} & \multicolumn{2}{c|}{2014} & \multicolumn{2}{|c|}{2019} \\
\cline { 2 - 7 } Class & $\begin{array}{c}\text { UA } \\
(\%)\end{array}$ & $\begin{array}{c}\text { PA } \\
(\%)\end{array}$ & $\begin{array}{c}\text { UA } \\
(\%)\end{array}$ & $\begin{array}{c}\text { PA } \\
(\%)\end{array}$ & $\begin{array}{c}\text { UA } \\
(\%)\end{array}$ & $\begin{array}{c}\text { PA } \\
(\%)\end{array}$ \\
\hline F & 96.11 & 97.74 & 93.98 & 92.31 & 98.83 & 96.02 \\
\hline NF & 94.74 & 91.14 & 85.56 & 88.51 & 91.76 & 97.50 \\
\hline $\begin{array}{c}\text { OA } \\
(\%)\end{array}$ & 95.70 & & 91.02 & 96.48 & \\
\hline KS & 0.8982 & 0.8014 & 0.9196 \\
\hline
\end{tabular}

F-Forest, NF-Non-Forest, OA - Overall Accuracy, KS- Kappa Statistics, UA User Accuracy, PA- Producer Accuracy

\section{B. LU/LC Change Analysis}

Due to the expansion of the human population and the industrial growth and other anthropogenic drivers, the LU/LC change was recognized as a critical part of research in the field of remote sensing [19] [20].
Table- IV: LU/LC CHANGE (2009 - 2014)

\begin{tabular}{|l|l|l|}
\hline \multicolumn{1}{|c|}{ LU/LC CHANGE } & Area (ha) & Percentage (\%) \\
\hline Forest - Forest & 1902.07462 & $62 \%$ \\
\hline Forest -- Non-Forest & 377.457415 & $12 \%$ \\
\hline Non-Forest - Forest & 122.215699 & $4 \%$ \\
\hline Non-Forest -- Non-Forest & 662.989017 & $22 \%$ \\
\hline
\end{tabular}

Over the many years, the land cover of the Javadi hills especially in forest had been used more significantly. Since, there is a need for information about the recent LU/LC changes that occurred in forest-covered areas of the Javadi hills, this work helps in providing the information to the land resource management to take necessary actions to prevent land resources in the future. LU/LC change analysis for the year 2009 to 2014 and 2014 to 2019 was performed and the results are presented in Tables IV and V.

Table- V: LU/LC CHANGE (2014 - 2019)

\begin{tabular}{|c|l|l|}
\hline LU/LC CHANGE & Area (ha) & Percentage (\%) \\
\hline Forest - Forest & 1645.643073 & $54 \%$ \\
\hline Forest -- Non-Forest & 371.576298 & $12 \%$ \\
\hline Non-Forest - Forest & 180.061045 & $6 \%$ \\
\hline Non-Forest -- Non-Forest & 848.630794 & $28 \%$ \\
\hline
\end{tabular}

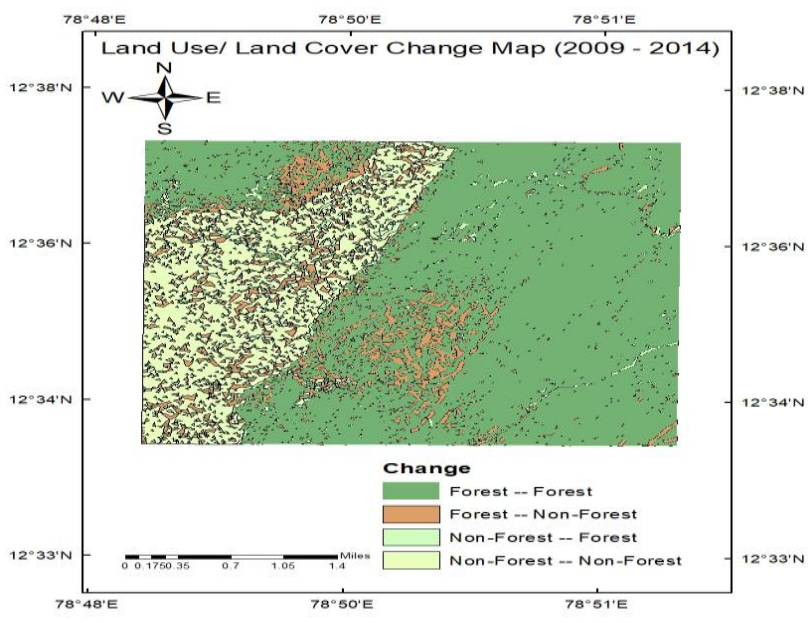

Fig. 6.LU/LC Change Map (2009 - 2014) 


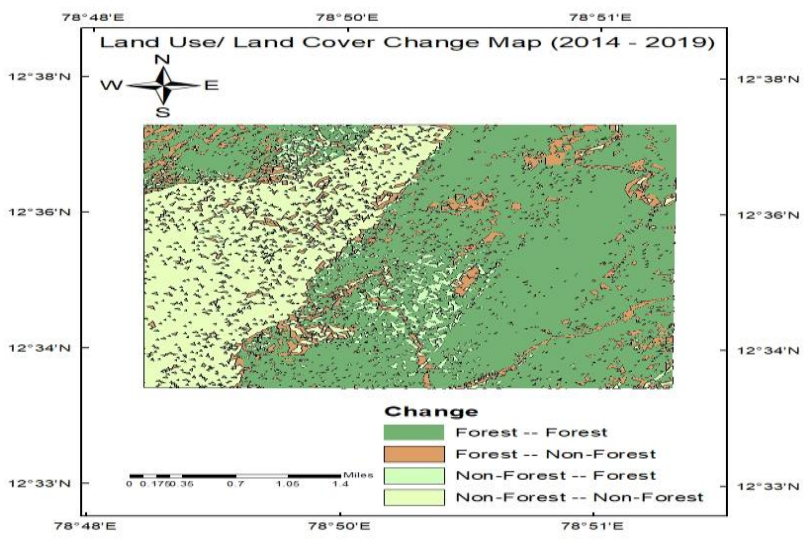

Fig. 7.LU/LC Change Map (2009 - 2014)

The study area was categorized as forest and non-forest cover region. From 2009 to 2014, 377.457415 ha of forest cover were converted to non-forest cover, 122.215699 ha of non-forest were converted to forest cover, 1902.07462 ha of forest cover and 662.989017 ha of non-forest cover remains under same LU/LC categories. From 2014 to 2019, 371.576298 ha of forest cover were converted to non-forest cover, 180.061045 ha of non-forest were converted to forest cover, 1645.643073 ha of forest cover and 848.630794 ha of non-forest cover remains under same LU/LC categories. The LU/LC change map for the different periods of 2009 to 2014 and 2014 to 2019 are shown in Fig. 6 and 7.

\section{LU/LC CHANGE (2009 -2014)}

$$
\begin{array}{ll}
\text { - Forest -- Forest } & \text { a Forest -- Non-Forest } \\
\text { Non-Forest -- Forest } & \text { von-Forest -- Non-Forest }
\end{array}
$$

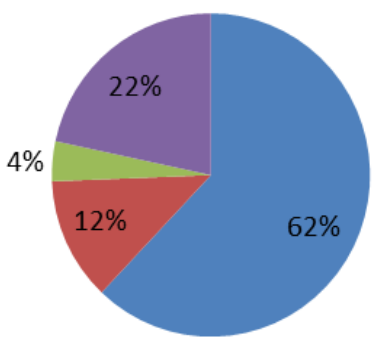

Fig. 8.Comparison of LU/LC Change from 2009 - 2014

The main goal of this work was to identify the percentage of LU/LC change that happened in the given study area. The result of this study shows that, for the year 2009 to $2014,12 \%$ of forest cover was changed to non-forest cover, $4 \%$ of the non-forest cover was changed to forest cover, and $62 \%$ of forest cover and $22 \%$ of non-forest cover remains same as before. For the year 2014 to $2019,6 \%$ of the non-forest cover is changed to forest cover, $54 \%$ of forest cover and $28 \%$ of non-forest cover remains the same as before and $12 \%$ of forest cover is changed to non-forest cover. The comparison chart is shown in Fig. 8 and 9.

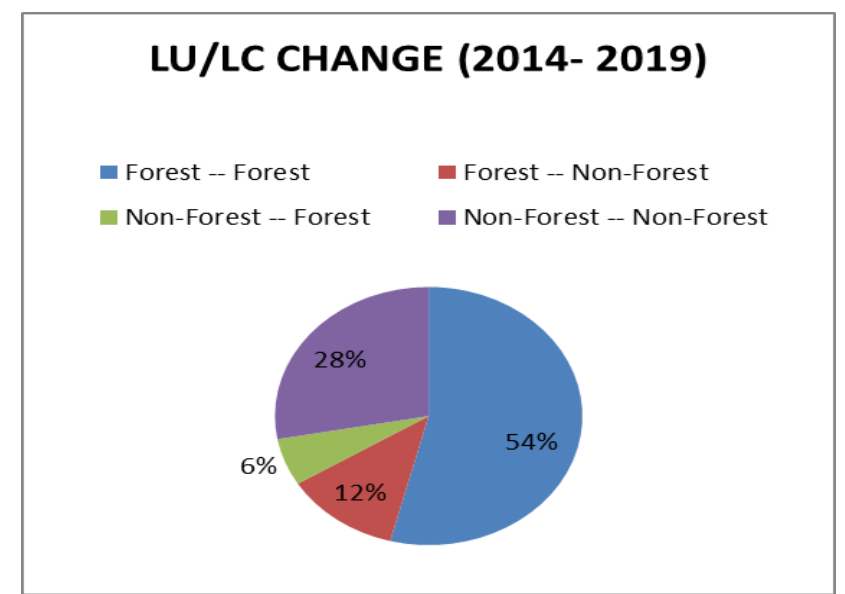

Fig. 9. Comparison of LU/LC Change from 2014 - 2019

\section{CONCLUSION}

LU/LC change reveals the major activities of humans on the environment and the natural resources. The satellite data for the years 2009, 2014 and 2019 had been pre-processed and classified into the forest and non-forest covered region. This work provides the advantage of using the hybrid classification technique of supervised and non-supervised classifiers which provides the enhanced accuracy results and hence helps in the further process of LU/LC change analysis for our study area. The utmost aim of this work was to identify the significant amount of LU/LC change that had been happened in the given study area for different five years span of 2009 to 2014 and 2014 to 2019. Apart from forest to forest and non-forest to non-forest, the results show that $12 \%$ of area has been changed from forest to non-forest for both the periods (2009 to 2014 and 2014 to 2019) and $4 \%$ of area had been changed from non-forest to forests for the year 2009 to 2014 and $6 \%$ of area had been changed from non-forest to forests for the year 2014 to 2019. The major changes that occurred in the study area help the decision-makers and other urban planners to make necessary actions over land resource management. This work provides the analysis that the deforestation is the main cause and it should be controlled and the government should make awareness to every human about the importance of having forest cover areas in the hilly region. This work on LU/LC change analysis in the Javadi hills was performed to initiate further researchers in finding the LU/LC change prediction for our study area.

\section{ACKNOWLEDGMENT}

Authors thank the United States Geological Survey (USGS) for providing Landsat 8 data, Bhuvan Indian Geo-Platform of Indian Space Research Organisation (ISRO) for providing the LISS - III data, and Google developers for providing the Google Earth Engine data. We are thankful to Vellore Institute of Technology (VIT) for providing the VIT SEED GRANT for carrying out this work and CDMM (Centre for Disaster Mitigation and Management),VIT for providing the good lab facility. 


\section{REFERENCES}

1. G Mishra, Prabuddh Kumar, Aman Rai, and Suresh Chand Rai. "Land use and land cover change detection using geospatial techniques in the Sikkim Himalaya, India." The Egyptian Journal of Remote Sensing and Space Science (2019).

2. Pande, Chaitanya B., et al. "Study of land use classification in an arid region using multispectral satellite images." Applied Water Science 8.5 (2018): 123

3. Manandhar, Ramita, Inakwu Odeh, and Tiho Ancev. "Improving the accuracy of land use and land cover classification of Landsat data using post-classification enhancement." Remote Sensing 1.3 (2009): 330-344.

4. Nagne, Ajay D., et al. "Land use land cover change detection by different supervised classifiers on LISS-III temporal datasets." 2017 1st International Conference on Intelligent Systems and Information Management (ICISIM). IEEE, 2017.

5. Heidarlou, Hadi Beygi, et al. "Effects of preservation policy on land use changes in Iranian Northern Zagros forests." Land Use Policy 81 (2019): 76-90.

6. Mabwoga, Samson Okongo, and Ashwani Kumar Thukral. "Characterization of change in the Harike wetland, a Ramsar site in India, using landsat satellite data." SpringerPlus 3.1 (2014): 576.

7. Karimi, Hazhir, et al. "Monitoring and prediction of land use/land cover changes using CA-Markov model: a case study of Ravansar County in Iran." Arabian Journal of Geosciences 11.19 (2018): 592.

8. Firoozynejad, M., and A. A. Torahi. "Evaluation of IRS1D-LISS-III and Landsat 8-OLI Images for Mapping in Maroon Riparian Forest." Iran. J Geogr Nat Disast 7.198 (2017): 2167-0587.

9. Mohajane, Meriame, et al. "Land Use/Land Cover (LULC) Using Landsat Data Series (MSS, TM, ETM+ and OLI) in Azrou Forest, in the Central Middle Atlas of Morocco." Environments 5.12 (2018): 131.

10. Alkaradaghi, Karwan, et al. "Evaluation of Land Use \& Land Cover Change Using Multi-Temporal Landsat Imagery: A Case Study Sulaimaniyah Governorate, Iraq." Journal of Geographic Information System 10.6 (2018): 247-260.

11. Shah, Shipra, and D. P. Sharma. "Land use change detection in Solan forest division, Himachal Pradesh, India." Forest Ecosystems 2.1 (2015): 26.

12. Sisodia, Pushpendra Singh, Vivekanand Tiwari, and Anil Kumar. "Analysis of supervised maximum likelihood classification for remote sensing image." International Conference on Recent Advances and Innovations in Engineering (ICRAIE-2014). IEEE, 2014.

13. Nithya, K., R. Shanmugasundaram, and N. Santhiyakumari. "Study of salem city resource management using k-means clustering." 2017 Conference on Emerging Devices and Smart Systems (ICEDSS). IEEE, 2017.

14. Venkateswaran, K., et al. "Performance Analysis of K-Means Clustering For Remotely Sensed Images." International Journal of Computer Applications 84.12 (2013).

15. Gashaw, Temesgen, et al. "Evaluation and prediction of land use/land cover changes in the Andassa watershed, Blue Nile Basin, Ethiopia." Environmental Systems Research 6.1 (2017): 17.

16. Cheruto, Mercy C., et al. "Assessment of land use and land cover change using GIS and remote sensing techniques: a case study of Makueni County, Kenya." (2016).

17. Hassan, Zahra, et al. "Dynamics of land use and land cover change (LULCC) using geospatial techniques: a case study of Islamabad Pakistan." SpringerPlus 5.1 (2016): 812.

18. Rwanga, Sophia S., and J. M. Ndambuki. "Accuracy assessment of land use/land cover classification using remote sensing and GIS." International Journal of Geosciences 8.04 (2017): 611.

19. Restrepo, Angela M. Cadavid, et al. "Land cover change during a period of extensive landscape restoration in Ningxia Hui Autonomous Region, China." Science of the total environment 598 (2017): 669-679.

20. Miheretu, Birhan Asmame, and Assefa Abegaz Yimer. "Land use/land cover changes and their environmental implications in the Gelana sub-watershed of northern highlands of Ethiopia." Environmental Systems Research 6.1 (2018): 7.

\section{AUTHORS PROFILE}

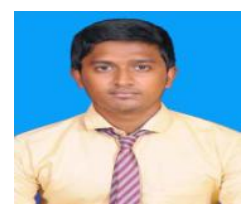

M. Sam Navin is a Research Scholar and working as the Teaching cum Research Assistant in the School of Information Technology and Engineering, Vellore Institute of Technology, Vellore, Tamil Nadu, India. He specializes in Remote Sensing, Machine Learning, Digital
Image Processing, Cloud Computing, Software Engineering, Internet of Things, Data Analytics, and he holds a first-class in Bachelor's degree in Computer Science and Engineering from Karunya University, Coimbatore, Tamil Nadu, India and Master's Degree in Software Engineering from St. Joseph's College of Engineering, Anna University, Chennai, India. Earlier in his career, he worked as a Teaching Assisstant at the School of Computer Science and Engineering, Sastra University, Thanjavur, Tamil Nadu, India. His research interest includes working with real time multispectral and hyperspectral data in the filed of remote sensing.

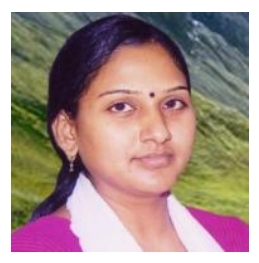

L. Agilandeeswari completed her $\mathrm{PhD}$ and working as HOD \& Associate Professor in the Department of Digital Communications, School of Information Technology \& Engineering (SITE), VIT Vellore. She also got best researcher award for the past four years from 2015 to till date. She received her Bachelor's degree in Information Technology and Master's in Computer Science and Engineering from Anna University during 2005 and 2009 respectively. She is having around $13+$ years of teaching experience and published 50+ papers in the peer reviewed reputed journals. Her reputed publications include research articles in peer reviewed journals namely Expert Systems with Applications, Journal of Ambient Intelligence and Humanized Computing, Multimedia Tools and Applications, Journal of Applied Remote Sensing. She is the peer reviewer in journals include IEEE Access, Array, Artificial Intelligence Review, Informatics in Medicine Unlocked, Neuro computing, Computers and Electrical Engineering, Journal of King Saud University - Computer and Information Sciences, IET Review, Journal of Engineering Science and Technology (JESTEC), etc. She also published about 13 engineering books as per Anna University Syllabus. She is a life time member in Computer Society of India. Her areas of interests include Image and video watermarking, Image and Video processing, Neural networks, Fuzzy Logic, Machine Learning, Cryptography, IoT, Information Centric Networks and Remote Sensing. 